\title{
Bioelectrochemical Systems, Energy Production and Electrosynthesis
}

\section{Abhijeet P. Borole ${ }^{1,2 \star}$}

${ }^{1}$ Biosciences Division, Oak Ridge National Laboratory, Oak Ridge, TN 37831, USA

2University of Tennessee, Center for Environmental Biotechnology, Knoxville, TN 37996, USA

"The submitted manuscript has been authored by UT-Battelle, LLC, under Contract No. DE-AC05-00OR22725 with the U.S. Department of Energy. The United States Government retains and the publisher, by accepting the article for publication, acknowledges that the United States Government retains a non-exclusive, paid-up, irrevocable, world-wide license to publish or reproduce the published form of this manuscript, or allow others to do so, for United States Government purposes".

Bioelectrochemical Systems (BES) such as microbial fuel cells and electrolysis cells have gained significant importance as sustainable systems for energy and chemical production over the last decade [1-3]. Their ability to treat waste, produce clean water as well as energy or chemicals gives these technologies a high prominence in the search for environmentally-friendly, $21^{\text {st }}$ century, energy technologies. Microbial Fuel Cells (MFCs), the most extensively studied BES system, generate electricity, a relatively inexpensive product. Due to the low price of electricity and a high capital cost (over $\$ 10,000 / \mathrm{m}^{3}$ ) [4], it is difficult to make an economic case for MFCs at this time. Microbial Electrolysis Cells (MECs), on the other hand, generate higher value products such as hydrogen, methane, etc, which makes them more feasible as far as economics is concerned. The performance of MECs necessary for practical application has been demonstrated at the laboratory scale [5], although long term performance results have not been forthcoming yet. Scale-up is a major issue and studies to date have shown significant hurdles in achieving the performance at the pilot scale [6]. Overcoming the bioelectrochemical losses at higher scales will require an integration of optimal design and process parameters [7] minimizing overgrowth of biofilms, requiring use of low cost separator media, use of hybrid electrodes maximizing surface area and electrical conductivity. Pilotscale studies investigating each of the scale-up factors will help move this technology towards commercialization. Continued research at the laboratory scale in development of cheaper materials including electrodes, membrane/separator and cathode catalysts will help improve the economic feasibility further.

Electrosynthesis has emerged as a new field of research in the last two years where electrical current is used for synthesis of fuels and chemicals. Biological as well as chemical catalysts are employed in the process. Electrosynthesis has evolved from bioelectrochemical research as renewable means of electricity production such as solar and winds have become practical. The field includes the specific area of electrofuels, which is production of transportation fuels starting from carbon dioxide [8] and production of chemicals such as hydrogen peroxide [9], caustic [10], 1,2-propanediol, etc. using suitable cathode catalysts. Current research is focused on synthetic biology to integrate pathways for carbon dioxide assimilation into biochemical building blocks such as acetyl CoA, assembly of biological circuits with redox enzymes to transport electrons from hydrogen, electricity or reduced chemicals to NADH and ATP production. The goal is to develop biosynthetic microbial catalysts with engineered circuits to produce fuels.

In order to realize the potential of electrofuels, significant effort is needed on the reactor and process side as well, since transforming energy from the electron sources to fuel is only one-half of the electrochemical reaction. Even with hydrogen as the electron and energy source, the oxygen atoms contained in carbon dioxide need to be transformed into a stable oxidized product (e.g., oxygen without affecting the fuel producing enzymes, some of which require strictly anaerobic conditions. Unless the counter reaction progresses to the same extent as the fuel production half-reaction, a charge imbalance will occur and halt the reaction. Research in understanding and catalyzing the oxidation half-reaction is therefore equally important. Recent scientific conferences have highlighted the growing interest in electrofuels research [11,12]. In the coming years may see a flurry of activity in this field as the research community tries to answer questions related to rates of electron supply to the microbes, determining practically feasible rates for producing fuel from carbon dioxide, managing bioelectrochemical losses related to scale-up of these systems, etc. Comparison of electrofuel processes with cellulosic biofuels and other methods of transforming raw materials into fuels, considering the whole life cycle, are also necessary to identify the most sustainable and practical paths forward. Potential to combine bioelectrochemical systems with more traditional biomass to biofuel processes have potential to improve process efficiencies further [13], but require techno-economic analysis to evaluate and guide improvements via the alternative process schemes.

Use of electrosynthesis for higher value chemical production is also likely to gain momentum in coming years [14]. The ability of microbes to accept and efficiently use electrons from the electrode to build chemical molecules using enzymes makes this field very attractive. However, the mechanism of extracellular electron transfer (from electrode to microbe) is poorly understood and is a subject of growing research interest. Nevertheless, the selectivity and efficiency afforded via a combination of biocatalysis and electrocatalysis make these systems highly attractive in terms of process and energy efficiency. There is also a need to build a bridge between the existing routes of biocatalytic pathways for chemical production to reagents and reducing equivalents that enter the cells from extracellular environment via biologically mediated electroactive structures. All these factors point to an exciting and intellectually stimulating atmosphere in this field of research in the near future.

*Corresponding author: Abhijeet P. Borole, Biosciences Division, Oak Ridge National Laboratory, Oak Ridge, TN 37831, USA, Tel: 865576 7421; Fax: 865 241 1555; E-mail: borolea@ornl.gov

Received November 22, 2012; Accepted November 26, 2012; Published November 29, 2012

Citation: Borole AP (2012) Bioelectrochemical Systems, Energy Production and Electrosynthesis. J Microbial Biochem Technol 4: xv-xvi. doi:10.4172/19485948.1000e112

Copyright: (C) 2012 Borole AP. This is an open-access article distributed under the terms of the Creative Commons Attribution License, which permits unrestricted use, distribution, and reproduction in any medium, provided the original author and source are credited 
Citation: Borole AP (2012) Bioelectrochemical Systems, Energy Production and Electrosynthesis. J Microbial Biochem Technol 4: xv-xvi. doi:10.4172/1948-5948.1000e112

\section{References}

1. Logan BE, Regan JM (2006) Microbial fuel cells--challenges and applications. Environ Sci Technol 40: 5172-5180.

2. Rozendal Rozendal RA, Hamelers HV, Rabaey K, Keller J, Buisman CJ (2008) Towards practical implementation of bioelectrochemical wastewater treatment. Trends Biotechnol 26: 450-459.

3. Rabaey K, Angenent LT, Schroder U, Keller J (2010) Bioelectrochemical Systems: From Extracellular Electron Transfer to Biotechnological Application. IWA Publishing, London, UK.

4. Sleutels TH, Ter Heijne A, Buisman CJ, Hamelers HV (2012) Bioelectrochemical systems: an outlook for practical applications. ChemSusChem 5: 1012-1019.

5. Jeremiasse AW, Hamelers HVM, Saakes M, Buisman CJN (2010) Ni foam cathode enables high volumetric $\mathrm{H}-2$ production in a microbial electrolysis cell. Int J Hydrogen Energy 35: 12716-12723.

6. Logan BE (2010) Scaling up microbial fuel cells and other bioelectrochemical systems. Appl Microbiol Biotechnol 85: 1665-1671.

7. Borole AP, Reguera G, Ringeisen B, Wang ZW, Feng Y, et al. (2011) Electroactive biofilms: Current status and future research needs. Energy Environ Sci 4: 4813-4834.
8. Harnisch F, Rabaey K (2012) The diversity of techniques to study electrochemically active biofilms highlights the need for standardization. ChemSusChem 5: 1027-1038.

9. Rozendal RA, Leone E, Keller J, Rabaey K (2009) Efficient hydrogen peroxide generation from organic matter in a bioelectrochemical system. Electrochem commun 11: 1752-1755.

10. Rabaey K, Bützer S, Brown S, Keller J, Rozendal RA (2010) High current generation coupled to caustic production using a lamellar bioelectrochemical system. Environ Sci Technol 44: 4315-4321.

11. http://electrofuels.aiche.org/webfm_send/29

12. Borole AP, Fischer C (2012) Electrofuels Biotechnology R\&D: Pathways and Processes to Drop-in Replacement Fuels. Biofuels and Biobased Chemicals Biotechnology Industry Organization, International Convention, Boston, USA.

13. Borole AP (2011) Improving energy efficiency and enabling water recycle in biorefineries using bioelectrochemical cells. Biofuels Bioproducts \& Biorefining 5: 28-36.

14. Rabaey K, Girguis P, Nielsen LK (2011) Metabolic and practical considerations on microbial electrosynthesis. Curr Opin Biotechnol 22: 371-377. 